English, please). It would then be up to Professor Meyer and his fellow non-AngloSaxons to assert themselves and their respective languages in a new "melting pot." -I am, etc.,

Therwii, Switzerland

S. C. COOPER

\section{Overseas Doctors}

SIR,-I agree with Dr. R. J. Henderson 26 July, p. 229) when he says, "How could a three-month habilitation course, especially for someone whose English is weak, make up for the deficiencies of several years in an inferior medical school?" Better facilities should be provided in Britain for training overseas doctors. Indian doctors do come to Britain out of altruism because they have a great respect for things British. If they had money on their mind they would have gone to oil-rich countries and to America. They come to Britain for postgraduate training instead of going to America, in spite of the fact that many British graduates receive postgraduate training in America. The image of Britain as a centre for postgraduate studies in medicine has been eroded. As a result overseas doctors in this country are drifting fast to America for postgraduate training.

There is no denying the fact that a strong emotional reaction against immigrants, once confined to shop floors, is now affecting the medical profession. This trend has been perceptibly growing over the past decade and has now come to a head. Cheap labour was welcome in the factories only during the depression of the 1930s. So was cheap medical labour welcome when the N.H.S. badly needed overseas doctors. The General Medica! Council has shown a lack of sensitivity in dealing with the issue. The human element has been missing. The G.M.C. knows as well as anyone else that spoken English can be picked up only by being in this country. The English themselves have difficulty in learning the dialects of Scotland. Overseas doctors should be accepted for training on a basis of equality In America after passing the E.C.F.M.G. one is accepted for training on an equal footing with an American for internship and residency. But for training in Britain there are no assurances and no safeguards.

When an overseas doctor in this country does not come up to expectation it tends to hit the headlines and the response of the mass media verges on hysteria. The B.M.A should have intervened before as well as a the present juncture. It should have suggested that discussions on examinations for overseas doctors and their results should be held behind the scenes.-I am, etc.,

Maesteg. Mid-Glamorgan

NESAR AHMED

\section{Primary Care and the Elderly}

SIR,-The R.M.F. is to be congratulated on giving rcasonably good coverage of the recent Annual Representative Meeting at Leeds and also of the Annual Scientitic Meeting 26 July, p. 221).

I think, however, that it is regrettable that in the account of the symposium on Primary Care and the Elderly no comment was made on the important discussion following a question I myself put to the panel concerning hearing aids and the elderly. This was accepted by the expert panel as of extreme importance. In addition, questions about the precise role of calcium supplements in both the skeletal system and maybe in the C.N.S. were rather summarily dismissed. Also, because of lack of time, a further question asking for the opinion of the panel on the acrimonious issue of euthanasia was conveniently dismissed, though at a time when there are so many experts clearly doing their utmost to further the care of the elderly there are yet other influential ones who support euthanasia. The B.M.A., quite rightly in my opinion has stated its view that euthanasia is to be condemned.'

The wider use of hearing aids would certainly help many of the elderly who find a progressive loss of hearing adding to a feeling of social isolation already present because of physical infirmities. Unfortunately attutudes to the physically disabled, aged or otherwisc infirm, are to say the least very laissez-faire. No wonder some imagine that some of their fellow human beings would be better out of this world! A little more thought and kindness might rectify this despicable attitude to the less privileged members of society.-I am, etc.,

Wetherby, Yorks

MaBEI, LOIS HaIGH

1 Britush. Medical fournai Supplement, 1969, 3, 66

\section{Control of Transient Cerebral Ischaemic} Altacks by Heparin

Sir,-We report the case of a patient with transient cerebral ischaemic attacks which did not respond to oral anticoagulants, but appeared to be effectively controlled by small doses of heparin given subcutaneously.

The patient, a previously healthy man aged 59, awoke in the night feeling unwell and unable to move his left arm. On arrival at hospital two hours later his disability had recovered completely. Next day, however, he began to have repeated attacks of a burning sensation around the nose and lips, slurred speech, and left-sided weakness. Subsequently the episodes of hemiparesis alternated between left and right. His blood pressure was $150 / 80 \mathrm{~mm} \mathrm{Hg}$ in both arms, all pulses were readily palpable, and no arterial bruits were heard. During attacks he exhibited dysarthria, nystagmus, and pyramidal signs in the limbs with sensory impairment sometimes on the right and sometimes on the left. He remained conscious and lucid throughout though he was incontinent on occasions. Transient ischaemic attacks in vertebrobasilar territory were diagnosed. His blood count, blood urea ritrogen, blood sugar, cholesterol, lipid profile, and tests for syphilis were satisfactory, as were radiographs of chest and skull. An E.C.G. showed a partial bundle-branch block attributed to ischaemia. A continuous heparin infusion $(10000 \mathrm{U}$ in $6 \mathrm{~h}$ ) was given on the third day in hospital and the ischaemic attacks ceased within hours. At the same time warfarin by mouth was given. After $48 \mathrm{~h}$ the heparin infusion was discontinued, but two days later the ischaemic attacks began again despite more than adequate oral anticoagulation (British Ratio 5.2). Attacks recurred with increasing frequency over the next five days, when heparin was reintroduced by the subcutaneous route in a dosage of $5000 \mathrm{U}$ every $12 \mathrm{~h}$ using a solution containing $25000 \mathrm{U} / \mathrm{ml}$. There were two further slight ischaemic attacks $48 \mathrm{~h}$ later, which then ceased. The injections were continued after discharge from hospital. Warfarin was withdrawn after a month without ill effect and the patient continued the heparin regimen for 10 weeks without complications. Two weeks after heparin was withdrawn the patient had one further attack and is currently taking aspirin and dipyridamole.

Several studies point to the usefulness of small doses of heparin given subcutaneously in preventing venous thrombosis after surgery. The precise way in which the low circulating levels of heparin act is not yet clear, but recent experimental work suggests this may be through enhancing the natural inhibitory property of plasma against thrombin and activated factor X.12 Theoretically the formation of thrombi within the arterial system may be less susceptible to influence by heparin, which can enhance the adriesion of platelets to collagen and their aggregation one to another. On the other hand, inhibition of the platelet release reaction by heparin may be more important in preventing subsequent embolization, and it is in this context that our observations are of interest. If confirmed they could provide a method of management in a clinical situation unresponsive to conventional therapy and fraught with the risk of a major stroke.-We are, etc..

Paul Millac KFITH WOOD

Departments of Neurology and Haematology, Royai Infirmary,

1 Han, P., and Ardlie, N. G., British Journal of Hacmatology, 1974, 27, 253.

Yin, E. T., Wessler, S., and Stoll, P., Fournal of
Bioligical Chemistry, 1971, 246, 3694, 3703 3712

Excessive Use of Psychiatric Services by Suicidal Patients

Sik,-I was somewhat surprised to find that in their paper (26 July, p. 216) Dr. D. J. Pallis and his co-workers quoted some figures I had reported at a conference in September 1974. In their introduction, when reviewing findings on the frequency of suicide attempts in psychiatric patients, they said: "A more recent survey in Oxford showed that one in every 11 inpatients or day-patients had attempted suicide over a six-month period -a rate of 8800 per 100000 patient population." I would like to comment on this statement partly for the sake of clarification. My study was a one-year prospective survey of persons carrying out deliberate acts of self-poisoning or self-injury while psychiatric inpatients or day-patients. In the context in which it occurred in Dr. Pallis and his colleagues' paper the statement could have been interpreted as referring to the number of patients found to have a previous history of such behaviour. I would in any case be loath to use the term "attempted suicide" to describe the majority of these acts since many involved, for example, minimal cutting of the skin.

Since the figures quoted referred to the first six months of the study and were provisional I feel I should give the final findings. The overall rate for this behaviour was 3330 per 100000 patients at risk (or one in every 30 ), which is considerably less than the figure that was quoted. Of more relevance to Dr. Pallis and his colleagues' study are my findings on scrutinizing the case notes of a consecutive series of 300 psychiatric hospital patients, when I found that at least 